\title{
Protroca: A Noninterventional Study on Prophylactic Lipegfilgrastim against Chemotherapy-Induced Neutropenia in Nonselected Breast Cancer Patients
}

\author{
Rachel Wuerstlein $^{\mathrm{a}, \mathrm{b}} \quad$ Nadia Harbeck ${ }^{\mathrm{a}, \mathrm{b}}$ Eva-Maria Grischke ${ }^{\mathrm{c}}$ Dirk Forstmeyer ${ }^{\mathrm{d}}$ \\ Raquel von Schumann ${ }^{\mathrm{e}}$ Petra Krabisch $^{f}$ Kerstin Lüdtke-Heckenkamp ${ }^{g}$ \\ Andrea Stefek $^{\mathrm{h}}$ Oliver Stoetzer ${ }^{\mathrm{i}}$ Andrea Grafe ${ }^{\mathrm{j}}$ Gabriele Kaltenecker $^{\mathrm{k}}$ \\ Helmut Forstbauer ${ }^{l}$ Doris Augustin ${ }^{m}$ Iris Schrader ${ }^{\mathrm{n}} \quad$ Joke Tio $^{\circ} \quad$ Ulrike Nitz $^{\mathrm{b}, \mathrm{e}}$ \\ Oleg Gluz ${ }^{\text {b, e, }}$ Ronald E. Kates ${ }^{\text {b }}$ Monika Karla Graeser ${ }^{\text {b, e }}$

\begin{abstract}
a Breast Center and CCC Munich, Department of Obstetrics and Gynecology, University of Munich (LMU), Munich, Germany; ${ }^{b}$ West German Study Group, Mönchengladbach, Germany; ' University Clinic Tübingen, Women's Clinic, Tübingen, Germany; ${ }^{d}$ University Clinic Leipzig, University Cancer Center Leipzig (UCCL), Leipzig, Germany; e Evangelical Hospital Bethesda, Breast Center Niederrhein, Mönchengladbach, Germany; ${ }_{i}^{f}$ Clinic Chemnitz, Breast Center, Chemnitz, Germany; ${ }^{9}$ Niels Stensen Clinics, Franziskus Hospital Harderberg, Georgsmarienhütte, Germany;

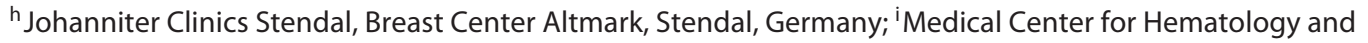

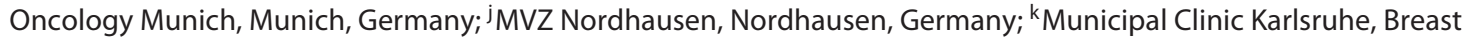
Center, Karlsruhe, Germany; 'Practice Network Troisdorf, Troisdorf, Germany; ${ }^{\mathrm{m}}$ Donau-Isar Clinic Deggendorf, Breast Center, Deggendorf, Germany; ${ }^{n}$ Gynecological Oncological Practice Hanover, Hanover, Germany; ${ }^{\circ}$ University Clinic Münster, Breast Center, Münster, Germany; PUniversity Hospital Cologne, Cologne, Germany
\end{abstract}

\section{Keywords}

Lipegfilgrastim · Chemotherapy · Breast cancer ·

Febrile neutropenia prophylaxis

\begin{abstract}
Background: Protroca evaluated the efficacy and safety of primary and secondary prophylaxis of neutropenia with lipegfilgrastim (Lonquex ${ }^{\circledR}$ ) in breast cancer patients receiving neoadjuvant or adjuvant chemotherapy (CT). Patients and Methods: Of the 255 patients enrolled, 248 patients were evaluable for the intent-to-treat (ITT) and 194 patients for the per-protocol set. Primary and secondary end points after lipegfilgrastim treatment were assessed. Results: Nine patients of the ITT set receiving lipegfilgrastim as primary prophylaxis ( $n=222$ ) had febrile neutropenia of grade 3-4 (5 patients) or infection of grade $3-4$ (4 patients); $1 / 26$ of those receiving secondary prophylaxis had an event. Dose reduc-
\end{abstract}

tions were performed in $9.5 \%$ of the patients. Postponement of cancer CT cycles for $>3$ days occurred in $<15 \%$ of patients; $10.8 \%$ (92/851 AEs) and 8\% (2/25 SAEs) of documented adverse events and serious adverse events, respectively, were related to lipegfilgrastim. Conclusions: Application of lipegfilgrastim was effective as primary and secondary prophylaxis in the prevention of CT-induced neutropenia in breast cancer.

(c) 2020 S. Karger AG, Basel

\section{Introduction}

Neutropenia and febrile neutropenia (FN) are frequent and potentially fatal toxicities of myelosuppressive cancer chemotherapy (CT) $[1,2]$. Using granulocyte colony-stimulating factors (G-CSFs) in clinical practice has remarkably reduced the duration and severity of neutro- 
penia, as well as the incidence of FN that allows chemotherapeutic treatment at the optimal dose and time with lower risk. In the dose-dense regimen ( $4 \times$ epirubicin, cyclophosphamide [EC] $\mathrm{q} 2 \mathrm{w}$ ), risk for FN with primary prophylaxis with G-CSF is reported as $3 \%$ per patient [35]. FN is commonly defined as fever $>38.5^{\circ} \mathrm{C}$ orally, or 2 consecutive readings of $>38.0^{\circ} \mathrm{C}$ during a 2 -h period, and an absolute neutrophil count (ANC) of $0.5 \times 10^{9} / \mathrm{L}$, or an expected ANC fall below $0.5 \times 10^{9} / \mathrm{L}$ [6]. CT-induced neutropenia can lead to CT cycle postponement or dose reductions, which may compromise treatment outcomes $[7,8]$. Lipegfilgrastim (Lonquex ${ }^{\circledR}$; Teva Ltd., Petach Tikva, Israel) is a novel long-acting glycopegylated G-CSF, which is an alternative to pegfilgrastim $\left(\right.$ Neulasta $\left.^{\circledR}\right)$ [9]. It binds to the human G-CSF receptor like filgrastim and pegfilgrastim. In contrast to the former drugs, lipegfilgrastim shows greater time-dependent resistance to neutrophil elastase degradation and greater retention of activity. This might contribute to the longer in vivo half-life of lipegfilgrastim [10]. Furthermore, lipegfilgrastim was more effective than the placebo in reducing the incidence and duration of severe neutropenia, as well as time to ANC recovery, in patients with non-small cell lung cancer receiving myelosuppressive therapy [11]. In randomized trials, lipegfilgrastim has shown to be equivalent to pegfilgrastim in reducing the incidence of severe neutropenia and FN in patients with breast cancer (BC) receiving CT with a similar safety profile [9]. Lipegfilgrastim obtained EMA (European Medicines Agency) regulatory approval to reduce both the duration of neutropenia and the incidence of CT-induced FN, and it was granted a marketing authorization valid throughout the European Union in 2013 [12]. It is approved for the reduction in the duration of neutropenia and the incidence of FN in adults treated with cytotoxic CT for malignancy (with the exception of chronic myeloid leukemia and myelodysplastic syndromes). The first approval study XM22-03 (breast cancer) for lipegfilgrastim showed the noninferiority of $6 \mathrm{mg}$ lipegfilgrastim to $6 \mathrm{mg}$ pegfilgrastim for the primary end point: duration of severe neutropenia in the first CT cycle. In the second approval study XM22-04 (nonsmall cell lung cancer), an approximately $50 \%$ lower incidence of duration of severe neutropenia, $\mathrm{FN}$, and severe neutropenia was seen [13]. The dosing recommended for lipegfilgrastim is $6 \mathrm{mg}$ for each CT cycle and should be given approximately $24 \mathrm{~h}$ after cytotoxic CT via the subcutaneous route [13]. In the West German Study Group (WSG) noninterventional study (NIS) Protroca (BfArM database: NIS-No. 6474), the efficacy and safety of primary and secondary prophylaxes with lipegfilgrastim on the incidence of FN and severe infection (SI) with prior or concurrent neoadjuvant or adjuvant treatment with dose-dense CT or with moderate-risk CT in nonselected $\mathrm{BC}$ patients in clinical routine were evaluated.

\section{Patients and Methods}

\section{Study Participants}

Between October 13, 2015, and September 25, 2017, a total of 255 patients were enrolled at 26 active sites. Protroca was reviewed and approved by the ethics committee. All registered patients gave written informed consent for study participation; there were no violations of inclusion or exclusion criteria. However, for 1 patient, only the registration form was filled in, and a further 6 patients had no lipegfilgrastim applications during CT. Thus, 248 patients remained who formed the intent-to-treat (ITT) set: 222 patients with primary and 26 patients with secondary prophylaxis. Of these, 194 patients had no postponement of CT cycles or dose reductions, thus yielding the per-protocol (PP) set: 171 patients with primary and 23 patients with secondary prophylaxis. Figure 1 provides an overview of the patients included in the study. The majority of patients received lipegfilgrastim as primary prophylaxis, i.e., 89.5 and $88.1 \%$ of ITT and PP patients, respectively; $10.5 \%$ of ITT patients got treatment with lipegfilgrastim as secondary prophylaxis mainly due to "prior occurrence of neutropenia without lipegfilgrastim treatment during a previous cycle of CT." Six of the 9 patients with previous G-CSF treatment other than lipegfilgrastim received pegfilgrastim.

\section{Patient Characteristics}

Median age of the patients receiving primary prophylaxis in the ITT set was 51 years (range: 24-81). Patients receiving secondary prophylaxis had a higher median age of 57 years (range: $38-76$ ) (Table 1).

\section{Study Design}

WSG-Protroca was an open, prospective NIS according to $\$ 4$ section 23 and $\$ 67$ section 6 of the German medicinal products act (AMG) conducted in Germany. Women with $\mathrm{BC}$ receiving CT or receiving concurrent neoadjuvant or adjuvant $\mathrm{CT}$ and for whom primary or secondary prophylaxis with lipegfilgrastim was recommended were enrolled. Diagnosis, treatment, and frequency of medical examinations followed daily routine practice and were not influenced by implementation of this NIS. Each patient was followed up for 30 days after the last administration of CT/lipegfilgrastim. Data were collected under routine medical practice conditions. In Protroca, 248 female patients with BC fulfilled the inclusion and exclusion criteria. The inclusion criteria were women with histologically confirmed BC, $\geq 18$ years of age, and concurrent neoadjuvant or adjuvant treatment by dose-dense CT, or by moderate-risk CT with risk factors (age $>65$ years and severe comorbidities).

\section{Objectives}

The primary end points were the combined occurrence of either FN or grade 3-4 SI requiring intravenous antibiotics evaluated in patients with primary and secondary prophylaxis with lipegfilgrastim, respectively. Secondary end points included dose reductions of further therapy (CT) after lipegfilgrastim treatment, cycle postponement of further therapy (CT) after lipegfilgrastim treatment, adverse events (AEs), and serious AEs (SAE) related to lipegfilgrastim according to NCI-CTCAE [14] (version 4.0), bone pain, neutropenia, and leukopenia related to lipegfilgrastim, and the lowest neutrophil count. Additionally, time to recovery from FN/SI following secondary prophylaxis was examined. Primary and secondary end points were analyzed for the ITT set; safety data were evaluated for both ITT and PP sets.

\section{Statistical Considerations}

Descriptive statistics for parameters was evaluated and reported as follows: for categorical variables, summary tabulations of the 
Table 1. Baseline characteristics (ITT)

\begin{tabular}{llll}
\hline Baseline characteristics & $\begin{array}{l}\text { Patients with } \\
\text { primary prophylaxis }\end{array}$ & $\begin{array}{l}\text { Patients with } \\
\text { secondary prophylaxis }\end{array}$ & ITT patients \\
\hline $\begin{array}{l}\text { Patients, } n(\%) \\
\begin{array}{l}\text { Age, years } \\
\text { Mean }\end{array}\end{array}$ & $222(100)$ & $26(100)$ & $248(100)$ \\
$\begin{array}{l}\text { Gender } \\
\text { Female }\end{array}$ & 51.70 & 57.42 & 52.30 \\
\hline
\end{tabular}

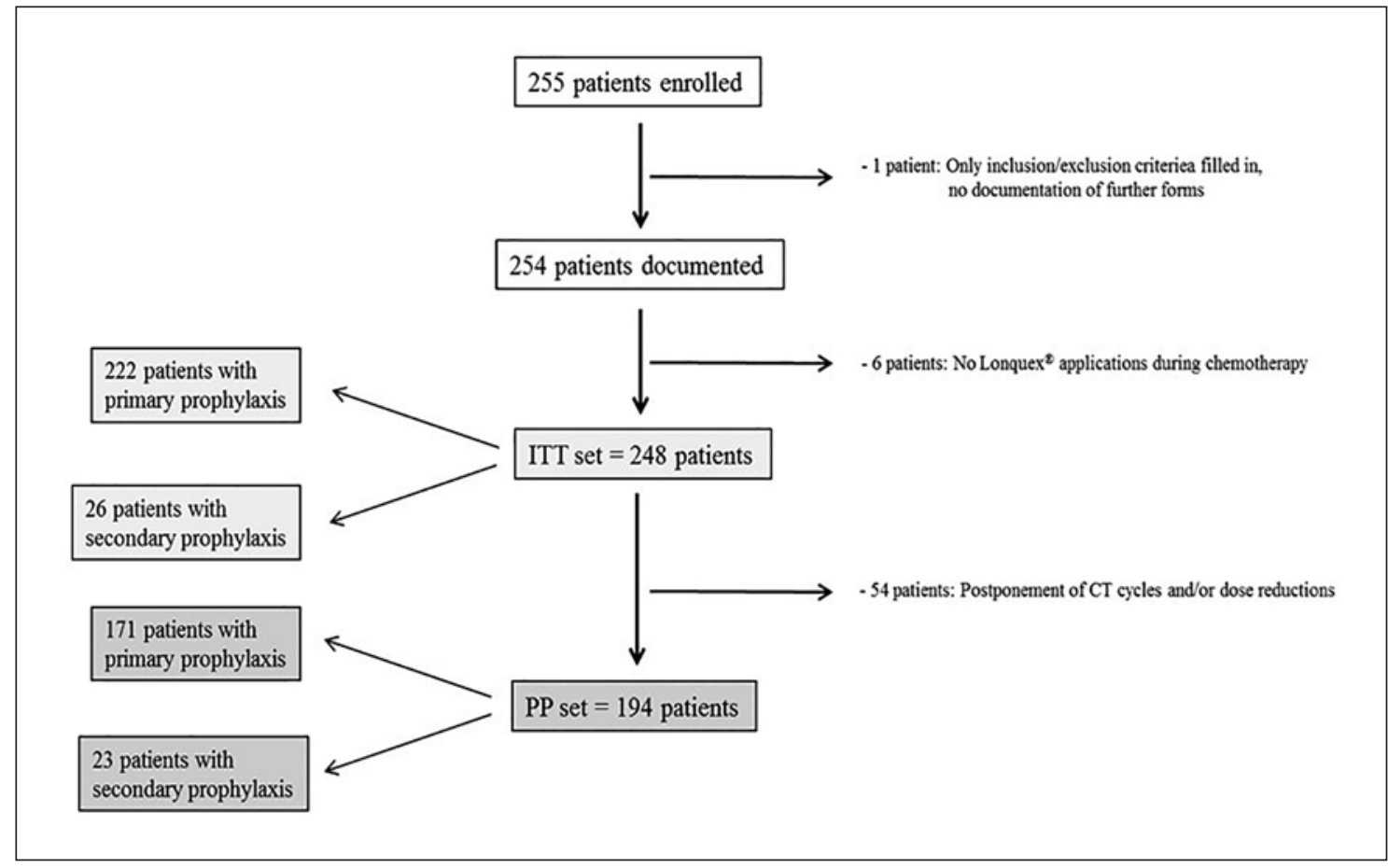

Fig. 1. Consort diagram. The ITT and PP sets consisted of 248 and 194 patients, respectively; 222 patients and 26 patients received primary and secondary prophylaxis, respectively, in the ITT set, and 171 patients and 23 patients received primary and secondary prophylaxis, respectively, in the PP set.

number and percentage within each category (with a category for missing data) of each parameter are presented. For continuous variables, number of observations, mean, standard deviation, quartiles (25th and 75th of the median), minimum and maximum values, as well as the number of missing observations are tabulated. To evaluate the primary end points (for primary and secondary prophylaxis), the odds ratios (ORs) of FN and SI (grade 3-4) are reported with $95 \%$ confidence intervals (CI) computed by normal approximation and by the Clopper-Pearson method. In case of zero events, exact upper confidence limits were computed from the binomial distribution.

\section{Results}

\section{Clinical Use of Lipegfilgrastim}

CT regimes with a 3-weekly interval were classified as conventional, those given biweekly as dose dense. This led to 4 groups of CT regimes: anthracycline (A)-containing dose-dense, A-containing conventional, non-A-containing dose-dense, and non-A-containing conventional groups. More than $80 \%$ of ITT had A-containing therapy, and nearly equal numbers of patients got either conventional or dose-dense A-containing therapy. The majority of patients with primary prophylaxis received A-containing dose-dense CT, those with secondary prophylaxis mainly received A-containing conventional CT (Table 2).

\section{Primary End Points}

Primary end points were evaluated in patients with primary and with secondary prophylaxis with lipegfilgrastim, respectively. The observed OR of either FN or grade 3-4 SI (requiring intravenous antibiotics) evaluated in patients with primary and secondary lipegfil- 
Table 2. CT regimes (ITT)

\begin{tabular}{|c|c|c|c|c|c|c|}
\hline & \multicolumn{2}{|c|}{$\begin{array}{l}\text { Patients with } \\
\text { primary prophylaxis }\end{array}$} & \multicolumn{2}{|c|}{$\begin{array}{l}\text { Patients with } \\
\text { secondary prophylaxis }\end{array}$} & \multicolumn{2}{|l|}{ ITT } \\
\hline & $n$ & $\%$ & $n$ & $\%$ & $n$ & $\%$ \\
\hline \multicolumn{7}{|c|}{ Anthracycline-containing CT } \\
\hline Dose dense & 105 & 47.30 & 4 & 15.38 & 109 & 43.95 \\
\hline Conventional & 86 & 38.74 & 18 & 69.23 & 104 & 41.94 \\
\hline \multicolumn{7}{|c|}{ Non-anthracycline-containing CT } \\
\hline Conventional & 29 & 13.06 & 4 & 15.38 & 33 & 13.31 \\
\hline Dose dense & 2 & 0.90 & - & - & 2 & 0.81 \\
\hline Patients, $n$ & 222 & 100.00 & 26 & 100.00 & 248 & 100.00 \\
\hline
\end{tabular}

The majority of patients with primary prophylaxis received anthracycline-containing dose-dense CT, those with secondary prophylaxis mainly received anthracycline-containing conventional CT.

Table 3. Event rates for the primary end point of the study: combined occurrence of FN and/or SI of grade 3-4 under primary and secondary prophylaxis in the ITT population

\begin{tabular}{lrrrl}
\hline Treatment & $n$ & \multicolumn{2}{c}{ Patients with FN and/or SI of grade 3-4 } & \multicolumn{2}{l}{\begin{tabular}{l} 
95\% CI (Clopper-Pearson), \\
\cline { 2 - 4 }
\end{tabular}} & $n$ & $\%$ & \\
\hline Primary prophylaxis & 222 & 9 & 4.05 & $1.87-7.56$ \\
Secondary prophylaxis & 26 & 1 & 3.85 & $0.10-19.64$ \\
ITT & 248 & 10 & 4.03 & $1.95-7.29$ \\
\hline
\end{tabular}

Table 4. Patients with FN of grade 3 or 4

\begin{tabular}{|c|c|c|c|c|}
\hline \multirow[t]{2}{*}{ Treatment } & \multirow[t]{2}{*}{$n$} & \multicolumn{2}{|c|}{ Patients with FN of grade $3-4$} & \multirow{2}{*}{$\begin{array}{l}95 \% \text { CI (Clopper-Pearson), } \\
\%\end{array}$} \\
\hline & & $n$ & $\%$ & \\
\hline Primary prophylaxis & 222 & 5 & 2.25 & $0.74-5.18$ \\
\hline Secondary prophylaxis & 26 & 0 & 0.00 & $0.00-13.23$ \\
\hline ITT & 248 & 5 & 2.02 & $0.66-4.64$ \\
\hline
\end{tabular}

2.0 and $2.3 \%$ of ITT and patients with primary prophylaxis had FN of grade $3-4$, respectively.

grastim prophylaxis, respectively, are shown with twosided Clopper-Pearson 95\% CIs in Table 3. The observed rate of these events in the ITT population receiving primary prophylaxis with lipegfilgrastim was $4.05 \%$ (95\% CI: $1.87-7.56 \%$ ). However (following a study amendment), the protocol specified testing the one-sided $95 \%$ upper confidence limit of the OR for primary prophylaxis against a desired limit of 5.3\%. The one-sided 95\% upper limit was $6.97 \%$, thus exceeding the desired protocol limit. For secondary prophylaxis, the observed OR was 3.85\% (95\% CI: $0.10-19.64 \%$ ). The protocol specified testing the one-sided $95 \%$ upper confidence limit: $16.98 \%$ against a desired limit of $15.0 \%$. Here again, the one-sided $95 \%$ upper limit exceeded the desired protocol limit. Although the upper $95 \%$ confidence limit of this occurrence rate for primary prophylaxis with lipegfilgrastim in the ITT population was approximately $7.6 \%$, so that the desired $95 \%$ upper confidence limit specified in the study protocol (5\%) was exceeded. For secondary prophylaxis, the $95 \%$ upper confidence limit was about $19.6 \%$, which also exceeds the desired limit of $15 \%$ specified in the protocol. Five ITT patients, all receiving lipegfilgrastim as primary prophylaxis, had FN with maximum grade 3 or 4 . Four patients had maximum grade 3 , and 1 patient suffered from FN of maximum grade 4 . The incidence number of FN per affected patient was 1 . None of the patients with secondary prophylaxis exhibited FN of grade 3 or 4 (Table 4). In total, 21 ITT patients suffered from infections, mainly of grade 1 or 2 maximally. Five patients had an infection of grade 3 or 4 
Table 5. SI (grade 3/4) rate (ITT)

\begin{tabular}{lrlcl}
\hline \multirow{2}{*}{ Treatment } & $n$ & \multicolumn{2}{l}{ Patients with SI of grade 3-4 } & \multirow{2}{*}{ 95\% CI (Clopper-Pearson), \% } \\
\cline { 3 - 4 } & & $n$ & $\%$ & \\
\hline Primary prophylaxis & 222 & 4 & 1.80 & $0.49-4.55$ \\
Secondary prophylaxis & 26 & 1 & 3.85 & $0.10-19.64$ \\
ITT & 248 & 5 & 2.02 & $0.66-4.64$ \\
\hline
\end{tabular}

$2.0,1.8$, and $3.9 \%$ of patients with ITT, primary or secondary prophylaxis had SI of grade 3-4, respectively.

Table 6. CT dose reductions (ITT)

\begin{tabular}{|c|c|c|c|c|c|c|}
\hline \multirow[t]{2}{*}{$\begin{array}{l}\text { Dose reduction in } \\
\text { chemotherapy }\end{array}$} & \multicolumn{2}{|c|}{$\begin{array}{l}\text { Patients with } \\
\text { primary prophylaxis }\end{array}$} & \multicolumn{2}{|c|}{$\begin{array}{l}\text { Patients with } \\
\text { secondary prophylaxis }\end{array}$} & \multicolumn{2}{|c|}{ ITT patients } \\
\hline & $n$ & $\%$ & $n$ & $\%$ & $n$ & $\%$ \\
\hline No & 201 & 90.54 & 26 & 100.00 & 227 & 91.53 \\
\hline Yes & 21 & 9.46 & - & - & 21 & 8.47 \\
\hline Total & 222 & 100.00 & 26 & 100.00 & 248 & 100.00 \\
\hline
\end{tabular}

9.5\% of patients receiving lipegfilgrastim as primary prophylaxis had CT dose reductions. Patients with secondary prophylaxis did not have any dose reductions.

Table 7. Cycle postponement of CT (ITT)

\begin{tabular}{|c|c|c|c|c|c|c|}
\hline \multirow[t]{2}{*}{$\begin{array}{l}\text { Postponement of } \\
\geq 1 \text { CT cycle(s) ( }>3 \text { days) }\end{array}$} & \multicolumn{2}{|c|}{$\begin{array}{l}\text { Patients with } \\
\text { primary prophylaxis }\end{array}$} & \multicolumn{2}{|c|}{$\begin{array}{l}\text { Patients with } \\
\text { secondary prophylaxis }\end{array}$} & \multicolumn{2}{|c|}{ ITT patients } \\
\hline & $n$ & $\%$ & $n$ & $\%$ & $n$ & $\%$ \\
\hline No & 190 & 85.59 & 23 & 88.46 & 213 & 85.89 \\
\hline Yes & 32 & 14.41 & 3 & 11.54 & 35 & 14.11 \\
\hline Total & 222 & 100.00 & 26 & 100.00 & 248 & 100.00 \\
\hline
\end{tabular}

$<15 \%$ of ITT patients had postponement of CT cycles for $>3$ days.

(Table 5). Among these patients, 1 patient with pneumonia of grade 3 received secondary prophylaxis, and the other 4 patients got primary prophylaxis with lipegfilgrastim. SI of these 4 patients were urinary tract infection, cystitis, and mucosal inflammation of grade 3 each and staphylococcal infection of grade 4 . The number of SI per affected patient was 1 .

\section{Secondary End Points}

Dose Reductions of Further Therapy (CT) after Lipegfilgrastim Treatment Start. More than $90 \%$ of patients in ITT and both subgroups had no dose reductions in concurrently given chemotherapeutic substances. Dose reductions were only performed in $9.5 \%$ of patients receiving lipegfilgrastim as primary prophylaxis. Patients with secondary prophylaxis had no CT dose reductions at all (Table 6).
Cycle Postponement of Further Therapy (CT) after Lipegfilgrastim Treatment Start. More than $85 \%$ of patients in the ITT group or subgroups had no shift in chemotherapeutic substance administration that was longer than 3 days (Table 7). Postponement of CT cycles for $>3$ days was observed in 14.4 and $11.5 \%$ of patients with lipegfilgrastim as primary and secondary prophylaxis, respectively.

\section{Safety}

$A E s$ and SAEs Related to Lonquex ${ }^{\circledR}$ according to NCI-CTCAE (Version 4.0). Drug-related AEs occurred in 38 ITT patients: 32 patients with primary and 6 patients with secondary prophylaxis (Table 8 ). Two patients (both receiving lipegfilgrastim as primary prophylaxis) each exhibited 1 drug-related SAE: fever (without neutropenia) of grade 3 with outcome "recovered/resolved without se- 
Table 8. Adverse events (AEs) and serious AEs (SAEs) in ITT $(n=248)$ and PP patients $(n=194)$

\begin{tabular}{|c|c|c|c|c|}
\hline \multirow[t]{2}{*}{ Treatment } & \multicolumn{2}{|c|}{ Patients with drug-related AEs } & \multicolumn{2}{|c|}{ Patients with drug-related SAEs } \\
\hline & $n$ & $\%$ & $n$ & $\%$ \\
\hline ITT & 38 & 15.32 & 2 & 0.81 \\
\hline Primary prophylaxis $(n=222)$ & 32 & 14.41 & 2 & 0.90 \\
\hline Secondary prophylaxis $(n=26)$ & 6 & 23.08 & - & - \\
\hline $\mathrm{PP}$ & 29 & 14.95 & - & - \\
\hline Primary prophylaxis $(n=171)$ & 24 & 14.04 & - & - \\
\hline Secondary prophylaxis $(n=23)$ & 5 & 21.74 & - & - \\
\hline
\end{tabular}

Lipegfilgrastim-related AEs/SAEs were more frequent in patients with secondary than primary prophylaxis.

Table 9. Drug-related AEs according to MedDRA-SOC and PT (event based, ITT/PP)

\begin{tabular}{|c|c|c|c|c|c|c|c|c|c|c|c|c|}
\hline \multirow[t]{2}{*}{$\begin{array}{l}\text { Drug-related AEs } \\
\text { (event based) }\end{array}$} & \multicolumn{2}{|c|}{$\begin{array}{l}\text { ITT: patients } \\
\text { with primary } \\
\text { prophylaxis }\end{array}$} & \multicolumn{2}{|c|}{$\begin{array}{l}\text { ITT: patients } \\
\text { with secondary } \\
\text { prophylaxis }\end{array}$} & \multicolumn{2}{|c|}{ ITT total } & \multicolumn{2}{|c|}{$\begin{array}{l}\text { PP: patients } \\
\text { with primary } \\
\text { prophylaxis }\end{array}$} & \multicolumn{2}{|c|}{$\begin{array}{l}\text { PP: patients } \\
\text { with secondary } \\
\text { prophylaxis }\end{array}$} & \multicolumn{2}{|c|}{ PP total } \\
\hline & $n$ & $\%$ & $n$ & $\%$ & $n$ & $\%$ & $n$ & $\%$ & $n$ & $\%$ & $n$ & $\%$ \\
\hline \multicolumn{13}{|c|}{ Blood and lymphatic system disorders } \\
\hline Leukocytosis & 1 & 1.27 & 3 & 23.08 & 4 & 4.35 & 1 & 1.61 & 3 & 25.00 & 4 & 5.41 \\
\hline Leukopenia & 1 & 1.27 & - & - & 1 & 1.09 & 1 & 1.61 & - & - & 1 & 1.35 \\
\hline Neutropenia & 2 & 2.53 & - & - & 2 & 2.17 & 1 & 1.61 & - & - & 1 & 1.35 \\
\hline Thrombocytopenia & 28 & 35.44 & 2 & 15.38 & 30 & 32.61 & 21 & 33.87 & 1 & 8.33 & 22 & 29.73 \\
\hline \multicolumn{13}{|c|}{ General disorders and administration site conditions } \\
\hline Chest pain & 1 & 1.27 & 2 & 15.38 & 3 & 3.26 & 1 & 1.61 & 2 & 16.67 & 3 & 4.05 \\
\hline Fatigue & 2 & 2.53 & - & - & 2 & 2.17 & 2 & 3.23 & - & - & 2 & 2.70 \\
\hline Pyrexia & 1 & 1.27 & - & - & 1 & 1.09 & - & - & - & - & - & - \\
\hline \multicolumn{13}{|c|}{ Immune system disorders } \\
\hline Hypersensitivity & 1 & 1.27 & - & - & 1 & 1.09 & 01 & 001.61 & - & & 1 & 1.35 \\
\hline \multicolumn{13}{|c|}{ Musculoskeletal and connective tissue disorders } \\
\hline Back pain & - & - & 1 & 7.69 & 1 & 1.09 & - & - & 1 & 8.33 & 1 & 1.35 \\
\hline Bone pain & 33 & 41.77 & 4 & 30.77 & 37 & 40.22 & 29 & 46.77 & 4 & 33.33 & 33 & 44.59 \\
\hline Myalgia & 9 & 11.39 & 1 & 7.69 & 10 & 10.87 & 5 & 8.06 & 1 & 8.33 & 6 & 8.11 \\
\hline Total AEs, $n$ & 79 & 100.00 & 13 & 100.00 & 92 & 100.00 & 62 & 100.00 & 12 & 100.00 & 74 & 100.00 \\
\hline
\end{tabular}

The proportion of patients in the PP set with thrombocytopenia was lower than the proportion of patients in the ITT set, whereas for bone pain a higher percentage of PP patients than ITT patients was observed. MedDRA, medical dictionary for regulatory activities; PT, preferred term; SOC, system organ class.

quelae" and thrombocytopenia of grade 4 with outcome "improved." Among patients who had no postponement of CT cycles or dose reductions of chemotherapeutic substances (PP set), no drug-related SAEs occurred. Proportions of patients with drug-related AEs were nearly similar between ITT and PP irrespective of primary or secondary prophylaxis (Table 7). Of the documented AEs in the ITT and PP set, $10.8 \%(92 / 851 \mathrm{AEs})$ and $11.6 \%$ (74/636 AEs), respectively, were related to lipegfilgrastim. Most frequently occurring drug-related AEs in both analysis sets were "bone pain" and "thrombocytopenia" (Table 9). Regarding patients with primary or secondary prophy- laxis, the percentages of patients with "leukocytosis" and "chest pain" were higher in patients with secondary prophylaxis than in those receiving primary prophylaxis. This was true for both analysis sets. Regarding the maximum grade per patient, most drug-related AEs were of grade 1 or 2 . The only reported drug-related AEs of grade 4 were neutropenia and thrombocytopenia observed in patients with primary prophylaxis (Table 10).

Occurrence of Bone Pain, Neutropenia, and Leukopenia Related to Lipegfilgrastim. The most frequent AEs for lipegfilgrastim as stated in the summary of product characteristics are musculoskeletal pain such as bone pain and 
Table 10. Bone pain, neutropenia, and leukopenia related to lipegfilgrastim (event based, ITT)

\begin{tabular}{|c|c|c|c|c|c|c|}
\hline \multirow{2}{*}{$\begin{array}{l}\text { Bone pain, neutropenia and } \\
\text { leukopenia related to } \\
\text { lipegfilgrastim }\end{array}$} & \multicolumn{2}{|c|}{$\begin{array}{l}\text { Patients with primary } \\
\text { prophylaxis }\end{array}$} & \multicolumn{2}{|c|}{$\begin{array}{l}\text { Patients with } \\
\text { secondary prophylaxis }\end{array}$} & \multicolumn{2}{|c|}{ ITT } \\
\hline & $n$ & $\%$ & $n$ & $\%$ & $n$ & $\%$ \\
\hline Bone pain & 33 & 91.67 & 4 & 100.00 & 37 & 92.50 \\
\hline Leukopenia & 1 & 2.78 & - & - & 1 & 2.50 \\
\hline Neutropenia & 2 & 5.56 & - & - & 2 & 5.00 \\
\hline Total & 36 & 100.00 & 4 & 100.00 & 40 & 100.00 \\
\hline
\end{tabular}

In the ITT set $(n=40), 37$ patients had bone pain, 1 had leukopenia, and 2 had neutropenia.

Table 11. Lowest neutrophil counts during therapy (ITT)

\begin{tabular}{lrrrrrrr}
\hline Treatment & $n$ & Mean & SD & Min & Median & Max & NMISS \\
\hline Primary prophylaxis, $10^{9} / \mathrm{L}$ & 173 & 11.74 & 118.90 & 0.00 & 2.10 & $1,566.00$ & 3 \\
$\quad \%$ & 46 & 37.85 & 21.51 & 0.00 & 37.35 & 78.70 & 0 \\
Secondary prophylaxis, $10^{9} / \mathrm{L}$ & 16 & 2.42 & 3.20 & 0.00 & 1.48 & 11.99 & 1 \\
$\quad \%$ & 9 & 46.04 & 28.38 & 0.00 & 44.00 & 83.90 & 0 \\
ITT, $10^{9} / \mathrm{L}$ & 189 & 10.95 & 113.76 & 0.00 & 1.93 & $1,566.00$ & 4 \\
$\quad \%$ & 55 & 39.19 & 22.68 & 0.00 & 38.30 & 83.90 & 0 \\
\hline
\end{tabular}

Median lowest neutrophil counts in ITT and both subgroups were reduced compared to normal laboratory values $\left(3.0-5.8 \times 10^{9} / \mathrm{L}\right.$ or $\left.50-70 \%\right)$. Maximum reported values exceeded normal values.

myalgia [13]. Three AEs, namely bone pain, neutropenia, and leukopenia, were examined closer (Table 10). Forty of these selected AEs were reported with bone pain making up the great majority of these 3 lipegfilgrastim-related AEs. Leukopenia and neutropenia were only observed in patients with primary prophylaxis.

Lowest Neutrophil Count. The lowest neutrophil granulocyte count during the period of combination treatment with CT and lipegfilgrastim was documented once after the end of therapy. The value could be reported in absolute $\left(\times 10^{9} / \mathrm{L}\right)$ or relative $(\%)$ terms. In ITT and both subgroups, at least 1 patient had lowest absolute and relative values of 0 , respectively. For ITT, calculation of median values yielded $1.9 \times 10^{9} /$ L (range: $0-1,566$ ) and $38.3 \%$ (range: $0-83.9$ ) (Table 11).

\section{Discussion}

The aim of WSG Protroca was to assess the efficacy and safety of primary and secondary prophylaxis of neutropenia with lipegfilgrastim $\left(\right.$ Lonquex ${ }^{\circledR}$ ) in BC patients receiving neoadjuvant or adjuvant treatment in routine practice. Following an amendment, 149 patients with primary and 97 patients with secondary lipegfilgrastim prophylaxis were to be recruited, respectively. The primary end points of WSG Protroca were the combined occurrence of events consisting of either FN or grade 3-4 SI (requiring intravenous antibiotics) evaluated in patients with primary and with secondary lipegfilgrastim prophylaxis, respectively. The observed rate of these events in the primary lipegfilgrastim prophylaxis group was $4.05 \%$ (9/222, ITT). The one-sided $95 \%$ upper confidence limit was $6.97 \%$, which exceeded the (amended) protocol limit of $5.3 \%$. For secondary prophylaxis, the observed rate was $3.85 \%(1 / 26$, ITT). The one-sided 95\% upper confidence limit was $16.98 \%$, exceeding the desired limit of $15.0 \%$. However, it is encouraging that the observed rates of these events were in line with or below expectations ( 3 and $10 \%$ for primary and secondary prophylaxis, respectively); pooling these data with data from other trials could tighten the limits. The observed $\mathrm{FN}$ rate was $2.25 \%$ for patients with primary prophylaxis. No patient with secondary prophylaxis exhibited FN. The observed FN rate is higher than the rate observed in 2 clinical trials assessing primary prophylaxis with lipegfilgrastim in $\mathrm{BC}$ patients, which was $0.7 \%$ for combined study analysis [15]. In the pivotal study, which enrolled patients with stage II-IV BC who received up to 4 cycles of doxorubicin and docetaxel, FN rates of 1.0 and $3.0 \%$ were observed in cycle 1 for 6 -mg lipegfilgrastim and 6-mg pegfilgrastim treatments, respectively [9]. The higher FN rate within Protroca compared to data of clinical trials may be due to the nonselected patient population enrolled in this NIS and the different CT regimes applied. 
Furthermore, within Protroca, the FN rate was calculated over all CT cycles and not only for the first cycle. In the NIS NADIR that investigated the use of lipegfilgrastim as prophylaxis for cancer patients, FN was only observed in patients receiving secondary prophylaxis and was 2.9 and $7.1 \%$ for all cancer and BC patients, respectively [16]. Patients with primary prophylaxis did not exhibit any $\mathrm{FN}$ in the first CT cycle of the NADIR study (rate $=0 \%$ ) in contrast to Protroca, where, in addition, all CT cycles were taken into account. In an American community-based study examining pegfilgrastim as primary prophylaxis in cancer patients, for patients with BC, a FN rate of 7.1\% across all CT cycles was described [17]. The observed SI rates were 1.8 and $3.9 \%$ for patients with primary and secondary prophylaxis, respectively. Because the group of patients with secondary prophylaxis was small and only 1 patient showed SI, the 3.9\% may represent an overestimate. Regarding the delay in CT treatment, in Protroca 4.4 and $11.5 \%$ of patients with primary and secondary prophylaxis, respectively, had a postponement of CT cycles. The percentage of delayed CT cycles was lower than in a randomized phase III clinical trial in which $30.7 \%$ of BC patients receiving primary lipegfilgrastim prophylaxis had delayed CT treatment [9]. Dose omissions or reductions in the lipegfilgrastim group were not observed [9], whereas in Protroca $9.5 \%$ of patients with primary prophylaxis had dose reductions. However, in the clinical trial, patients with high-risk stage II, III, or IV BC receiving a maximum of 4 cycles with doxorubicin/docetaxel were enrolled [9]. In Protroca, there were no specifications regarding CT drugs or maximum number of cycles. Dose reduction or cycle delay was decided solely by the investigator. Regarding safety, $14.4 \%$ (14.0\%) and 23.1\% (21.7\%) of ITT patients (PP) with primary and secondary prophylaxis experienced drug-related AEs. Drug-related SAEs only occurred in $0.9 \%$ of ITT patients with primary prophylaxis. In accordance with the summary of product characteristics [13], the most frequently occurring drugrelated AEs in both analysis sets were "bone pain" and "thrombocytopenia" with 10.9 and $3.6 \%$ of patients, respectively. In addition, the occurrence of bone pain, neutropenia, and leukopenia assessed as related to lipegfilgrastim were analyzed separately. Bone pain made up the great majority of these 3 AEs associated with lipegfilgrastim. Neutropenia and leukopenia, which may indicate nonefficacy of lipegfilgrastim treatment, occurred in patients with primary prophylaxis only. Most patients had grade 1 or 2 of these respective adverse drug reactions. The rate of patients with bone pain in Protroca was higher than in NADIR, in which $2.7 \%$ of patients suffered from bone pain. Regarding clinical trials, patients using lipegfilgrastim prophylaxis and exhibiting bone pain varied from 20.0 [18] to $23.8 \%$ [9]. In contrast to Protroca, the rate refers to patients with AEs, not reactions, in the clinical trials. Ad- ditionally, as mentioned above, in NIS adverse reactions and AEs may be underrepresented due to nonsystematic collection of these parameters at the sites. The majority of all documented AEs in Protroca belonged to "blood and lymphatic system disorders" and "gastrointestinal disorders," which is in accordance with the use of chemotherapeutic substances. One patient died due to "sudden cardiac death" not related to lipegfilgrastim. Dose-dense CT is a widely used therapy strategy, and using the same doses as in 3-weekly therapy in a 2-weekly setting is only feasible with appropriate support, e.g., G-CSF treatment, to prevent neutropenia. In conclusion, lipegfilgrastim was effective as primary and secondary prophylaxis in the prevention of CT-induced neutropenia. Observed adverse drug reactions and adverse events were in line with the lipegfilgrastim summary of product characteristics and the administered CT; no new toxicities were identified.

\section{Acknowledgments}

We thank the patients and the doctors, nurses, and trial coordinators who participated in the Protroca study. We also thank WSG GmbH for trial management.

\section{Statement of Ethics}

All procedures performed in studies involving human participants were in accordance with the ethical standards of the institutional and/or national research committee and with the $1964 \mathrm{Hel}-$ sinki Declaration and its later amendments or comparable ethical standards.

All registered patients gave written informed consent for study participation; there were no violations of inclusion or exclusion criteria.

\section{Disclosure Statement}

Rachel Wuerstlein received personal fees/travel support from Agendia, Amgen, Astra Zeneca, Boehringer Ingelheim, Carl Zeiss, Celgene, Daiichi-Sankyo, Esai, Genomic Health, Glaxo Smith Kline, Hexal, Lilly, MSD, Mundipharma, NanoString Technologies, Novartis, Odonate, Paxman, Palleos, Pfizer, Pierre Fabre, PumaBiotechnology, Riemser, Roche, Sandoz/Hexal, Seattle Genetics, Tesaro Bio, and Teva. Nadia Harbeck received personal fees (lectures and/ or consulting) and research funding from Amgen, Celgene, Genomic Health, NanoString Technologies, Novartis, Pfizer, Roche, AstraZeneca, Hexal, Roche/Genentech, Sandoz, and Boehringer Ingelheim (Inst). Ulrike Nitz received personal fees from Genomic Health and Roche. Oleg Gluz received personal fees/travel support from Genomic Health, NanoString Technologies, Roche, Celgene, and Teva. Eva-Maria Grischke received personal fees from Roche. Dirk Forstmeyer received personal fees (speaker's bureau and consulting) from Pfizer, Novartis, Roche, and MSD.

\section{Funding Sources}

This study was funded by Teva Biotech. 


\section{Author Contributions}

Study conception and design were performed by Rachel Wuerstlein, Nadia Harbeck, and Ronald E. Kates, and administrative support by Ulrike Nitz.
All authors contributed to collection and assembly of data, provision of study material or inclusion of patients, and manuscript writing; gave final approval to the manuscript; and were accountable for all aspects of the work. Ronald E. Kates, Rachel Wuerstlein, and Monika Graeser contributed to data analysis and interpretation.

\section{References}

1 Kuderer NM, Dale DC, Crawford J, Cosler LE, Lyman GH. Mortality, morbidity, and cost associated with febrile neutropenia in adult cancer patients. Cancer. 2006 May; 106(10):2258-66

2 Pfeil AM, Allcott K, Pettengell R, von Minckwitz G, Schwenkglenks M, Szabo Z. Efficacy, effectiveness and safety of long-acting granulocyte colony-stimulating factors for prophylaxis of chemotherapy-induced neutropenia in patients with cancer: a systematic review. Support Care Cancer. 2015 Feb;23(2):525-45.

3 Lyman GH, Delgado DJ. Risk and timing of hospitalization for febrile neutropenia in patients receiving $\mathrm{CHOP}$, $\mathrm{CHOP}-\mathrm{R}$, or $\mathrm{CNOP}$ chemotherapy for intermediate-grade nonHodgkin lymphoma. Cancer. 2003 Dec;98 (11):2402-9.

4 Wolff D, Culakova E, Poniewierski MS, Lyman GH, Dale DC, Crawford J; Awareness of Neutropenia in Chemotherapy Study Group. Predictors of chemotherapy-induced neutropenia and its complications: results from a prospective nationwide registry. J Support Oncol. 2005 Nov-Dec;3(6 Suppl 4):24-5.

5 Crawford J, Dale DC, Kuderer NM, Culakova E, Poniewierski MS, Wolff D, et al. Risk and timing of neutropenic events in adult cancer patients receiving chemotherapy: the results of a prospective nationwide study of oncology practice. J Natl Compr Canc Netw. 2008 Feb; 6(2):109-18.

6 Lyman GH, Kuderer NM. Epidemiology of febrile neutropenia. Support Cancer Ther. 2003 Oct;1(1):23-35
7 Lyman GH. Impact of chemotherapy dose intensity on cancer patient outcomes. J Natl Compr Canc Netw. 2009 Jan;7(1):99-108.

8 Swain SM, Tang G, Geyer CE Jr, Rastogi P, Atkins JN, Donnellan PP, et al. Definitive results of a phase III adjuvant trial comparing three chemotherapy regimens in women with operable, node-positive breast cancer: the NSABP B-38 trial. J Clin Oncol. 2013 Sep; 31(26):3197-204.

9 Bondarenko I, Gladkov OA, Elsaesser R, Buchner A, Bias P: Efficacy and safety of lipegfilgrastim versus pegfilgrastim: a randomized, multicenter, active-control phase 3 trial in patients with breast cancer receiving doxorubicin/docetaxel chemotherapy. BMC Cancer. 2013 Aug; 13:386.

10 Guariglia R, Martorelli MC, Lerose R, Telesca $\mathrm{D}$, Milella MR, Musto P: Lipegfilgrastim in the management of chemotherapy-induced neutropenia of cancer patients. Biologics. 2016 Jan; 10:1-8.

11 Volovat C, Bondarenko IM, Gladkov OA, Elsasser R, Buchner A, Bias P, et al: Phase III, randomized, double-blind, placebo-controlled, multicenter study of lipegfilgrastim in patients with non-small cell lung cancer receiving myelosuppressive therapy. Springerplus. $2015 \mathrm{Jul} ; 4: 316$

12 Assessment report lonquex [last accessed 2019 March 4]. Available from: http://www. ema.europa.eu/docs/en_GB/document_ library/EPAR_-_Public_assessment_report/ human/002556/WC500148382pdf, Last accessed on 4th March 2019.
13 Smpc lonquex. Available from: https://www. ema.europa.eu/en/documents/productinformation/lonquex-epar-product information_en.pdf.

14 Common terminology criteria for adverse events v3.0 (ctcae) [last accessed 2019 March 4]. Available from: https://ctep.cancer. gov/protocolDevelopment/electronic_ applications/docs/ctcaev3.pdf.

15 Bond TC, Szabo E, Gabriel S, Klastersky J, Tomey O, Mueller U, et al. Meta-analysis and indirect treatment comparison of lipegfilgrastim with pegfilgrastim and filgrastim for the reduction of chemotherapy-induced neutropenia-related events. J Oncol Pharm Pract. 2018 Sep;24(6):412-23.

16 Kurbacher CM, Fietz T, Diel IJ, Egert M, Hurtz HJ, Lück A, et al. NADIR: A non-interventional study on the prophylaxis of chemotherapy-induced neutropenia using lipegfilgrastim - first interim analysis. Oncol Res Treat. 2015;38(5):221-9.

17 Ozer H, Mirtsching B, Rader M, Luedke S, Noga SJ, Ding B, et al. Neutropenic events in community practices reduced by first and subsequent cycle pegfilgrastim use. Oncologist. 2007 Apr;12(4):484-94.

18 Buchner A, Elsässer R, Bias P. A randomized, double-blind, active control, multicenter, dose-finding study of lipegfilgrastim (XM22) in breast cancer patients receiving myelosuppressive therapy. Breast Cancer Res Treat. 2014 Nov;148(1):107-16. 